\title{
PRINCIPLES OF CASE WORK WITH THE FEEBLE-MINDED
}

\author{
By Catherine Brannick, M.D., \\ Psychologist, Massachusetts Reformatory for Women.
}

The subject of feeble-mindedness is now recognized as one of the most important educational and social problems of the day because of its relation to other social problems. Various researches have shown that it complicates practically every one of our social questions, poverty and dependence, delinquency, vice and crime, inebriety, vagrancy, unemployment and industrial inefficiency. Numbers and relative increase are the important factors in the problem: it is estimated that three in every one thousand individuals in the United States are feeble-minded, making a total on this basis of 275,000 ; in proportion to their population they are increasing at practically twice the rate of the normal population. The burden is heaviest in the fields of delinquency and crime: 48,000 feebleminded persons are committed yearly to correctional institutions in the United States, and the percentage of feeble-minded within these institutions is variously estimated from 15 per cent to 50 per cent.

As research has demonstrated the widespread significance of the problem, methods of meeting it have multiplied, with the idea of prevention leading. At present thirty-two states make some provision for this group in special institutions. In many cities special classes have been established under the public school system providing a curriculum adapted to their needs. A few states have passed permissive laws providing for sterilization and in effect debarring marriage under certain conditions. The department of immigration has recognized the problem by more careful examination and observation of the immigrant. An educational campaign has been directed by numerous organizations throughout the country interested in eugenics and mental hygiene and a special committee, national in scope, was organized in 1915 with objects "to disseminate knowledge concerning the extent and menace of feeblemindedness and to suggest and initiate methods for its control and ultimate eradication from the American people."

All forms of treatment revolve about the special institution for

60 
training and segregation, but it has come to be accepted that it is impracticable and even undesirable to work for such provision for all members of the group. There can be no question but that institutional treatment is the most economical and the only rational one in the case of the low grade, the intractable and the clearly unprotected. On the other hand, it is quite as evident that given proper personal and social treatment, many more of the group will be safe and fairly useful members of the community. These two ideas, segregation limited or permanent, and special training with directed oversight in the community, are the guiding principles of the plan of treatment outlined by the mature and progressive students of the problem. In Massachusetts, which already leads in its provision for the feeble-minded, a state program has been outlined by the League for Preventive Work which methodizes these ideas. The program, known as the Fernald plan, provides care for the known defectives according to their individual needs and methods of finding others. It includes:

(1) A state commission

(a) for friendly guidance of mental defectives who under supervision can live wholesome lives in the community,

(b) with authority to safeguard in a state school those who cannot.

(2) A state-wide census of the uncared-for feeble-minded

(3) Clinics for mental examination easy to reach from all parts of the state

(4) Special classes in public schools for mentally defective children

(5) Special treatment by the courts of mentally defective delinquents

(6) Completion of a third school for the feeble-minded

In addition, the State Board of Education is "planning a Statewide investigation to determine the number of subnormal children not being provided for in institutions," with the idea of formulating a state-wide policy for the special training of these children. It is hardly probable that such a model plan can soon be carried out in its entirety even in the most progressive states. Certain of its most important principles can be tried out, however, even in those states which are most backward in providing for the feeble-minded and chief of these is the principle of individualization of treatment.

The idea of applying this principle to work with mental defectives is new and as yet not very acceptable to the general social worker. In the words of one of these workers, "there's no such animal as case work with the feeble-minded." The assumption has 
been that once an individual has been diagnosed as mentally defective, there is nothing more to be done unless he can be shut up in an institution. This attitude disregards the facts that variations and types of mental defectives are as many as among the normal; that many who must be graded as mentally defective are in a limited degree socially competent, are making a poor but adequate living, and so have escaped the attention of the social agencies; that social incompetence or inability to manage one's own affairs as used in the definition of feeble-mindedness may be modified by special training and oversight.

Recent figures of psychological tests given to the drafted men of the United States Army show that approximately 2 per cent of the men are mentally inferior. Their services, nevertheless, are to be used within the army in forms of work suited to their intelligence, -in the care of horses, carting, road repairing, etc. The inference is that there had been no expression of social deficiency, to any degree, in these men previously.

Feeble-mindedness is best defined as "social incompetence due to arrested mental development." It is therefore more inclusive than the term "mentally defective" and is used in a double sense,-a psychological and a social one. It does not imply an absolute lack of possibility for social competence, but only a limited or relative one. The definition of the British Royal Commission (1908) specifically defines an individual of the highest grade of feeblemindedness as one "capable of earning a living under favorable circumstances, but incapable from mental defect existing from birth or from an early age of competing on equal terms with his normal fellows, or of managing himself and his affairs with ordinary prudence." In practice, the two aspects of feeble-mindedness, defective intelligence and social deficiency, are found combined in varying degrees. Many of the relatively low grades of intellectual defect show no special anomaly of temperament and disposition and grade fairly high by the social test; many others who grade relatively high in the psychological sense show such temperamental eccentricities as to make social adjustment impossible.

Although constructive work with the feeble-minded outside of institutions is as yet comparatively new and undeveloped, it has already demonstrated the possibilities of modifying the social inefficiency in certain types so that they are acceptable and fairly 
useful members of society. Classes for subnormal children in Springfield, Massachusetts, in Boston, New York and other cities not only have given specialized education and training, but through the personal interest of the teachers or specially appointed visitors from the schools, the children have been followed into their working life and the necessary help and supervision given in industrial adjustments.

It is well to dwell on the hopeful and positive aspects of individual treatment of this group for, whether the eugenist and social reformer will or no, the feeble-minded will still remain in the community. In Massachusetts, the leading state in institutional provision for the feeble-minded, there are as yet only one-fifth of the estimated number in the state so cared for.

Since institutional care for all of the group is obviously out of the question, the next consideration is the classification of types to fit the two main divisions of treatment, institutional and community. This classification would be based on considerations covering in general the personal and social factors in the make-up and immediate surroundings of the individual, as:

(a) Age

(b) Degree of mental defect

(c) Inherent and innate characteristics other than the purely intellectual

(d) Possibilities for special training in the community

(e) Possibilities for protection and supervision

(f) Development or no of anti-social habits

Feeble-minded women who have passed the active sexual period and show no special emotional irregularities should be able to fit into community life under supervision. Men with no antisocial tendencies are often found self-supporting and fairly useful workers in many of the lower forms of industry. These are the men so often described by their employers as "honest, faithful and industrious, but not over bright." Very young children should not be allowed to crowd the institutions for the feeble-minded, to the neglect of more urgent and suitable cases. Frequently parents ask for the commitment of such children to be rid of their care, and social workers are often found aiding or encouraging this, though the case may present no special problem in itself nor even in its relation to the family problem.

It is of course self-evident that the lowest grades of mental 
defectives, even young children, unless physically and socially well cared for, should be in institutions. This is the type which fits very fairly into other institutions than the special ones for defectives. Above these grades, the decision as to the form of treatment will be based more largely on the temperament and disposition of the feeble-minded individual than on the degree of purely intellectual defect. Even when the community offers good opportunity for special training, the decision between institutional and community care will still depend on the individual, on the probabilities that he can be made industrially and socially efficient to some degree. Is there possibility of adequate protection and supervision? Has he the physical capacity to get on outside an institution? Are his innate tendencies such that he is unlikely ever to fit into community life? Is he lazy, cruel to his weaker companions, sexually overactive? Is he innately irritable, stubborn, destructive and abusive in temper? Is he untruthful, sly or thieving? If these or other innate tendencies that have an anti-social bearing are present in the feeble-minded, then institutional treatment is the choice, irrespective of degree of mental defect, or special ability along industrial lines, or opportunity for training in the community.

Any industrial or reform school can give plenty of evidence that it is not the intellectually higher types that should be kept out of institutions for the feeble-minded. The directors of these schools complain that most of their troubles of a disciplinary nature can be traced to these defectives, and one director goes so far as to say that there is no incorrigible prisoner in his reformatory who is not subnormal.

As found on commitment, there is no doubt but that the majority of these defective delinquents are troublesome beings, but there is always the question whether a certain number might not have been improved to the point of relatively fair social competence by individual treatment in the community earlier. When a feebleminded boy or girl is recognized as such for the first time in a reform school, it is sometimes difficult to separate innate characteristics from acquired bad habits and influence of environment. Mental defect and mental instability frequently are present in the same individual, but the instability observed in the adult feeble-minded is undoubtedly due in some instances to environmental over-stimulation acting on defective inhibitory powers. This is illustrated in 
reformatory experience the opposite of that of the superintendent's described above, and it sometimes happens that a feeble-minded individual, whose conduct in the community kept his relatives and the police busy, gives no trouble when under restraint in an even environment.

The classification of defectives for the purpose of outlining treatment should form a part of the diagnosis in every case, and for this reason is work for the expert, capable of giving clinical consideration to all the characteristics of the individual, physical, mental and temperamental, and of evaluating them in their relation to his environment. A simple diagnosis without recommendation is not much more helpful in the fields of psychology and psychiatry than in the field of general medicine. Any one who has had to deal with problems of delinquency or other forms of conduct disturbance, knows that when the psychologist has said that an individual is or is not feeble-minded, he has said the least that can be said. If the person is feeble-minded, the conduct disturbance may or may not be directly related to the mental defect, while the bald statement that he is not feeble-minded leaves his conduct disturbance wholly unexplained. An interpretation of the individual is the only helpful diagnosis and is as important in the case of the feeble-minded as with the intellectually normal who present behavioristic problems.

Such interpretation is absolutely essential to the intelligent handling and oversight of the feeble-minded in the community. The outlook at best may not be encouraging but the problem is there and must be met. All too frequently it happens that the institution is non-existent and that the community form of treatment is the only possible one. When one knows the individual, that he is defective to a stated degree, that his defect is or is not transmissible, that he has certain socially favorable characteristics that must be deliberately fostered or socially negative tendencies that must be deliberately repressed, it is possible to work with hope that is not overhopeful.

In the handling of feeble-minded children in the community, one can do no better than borrow from the principles and methods of the special institutions and classes that have already been successful with them. The most successful of these appear to have applied education to defective children in its literal sense, a "drawing out" what is in the child more than a "pouring in," irrespective 
of ability to hold or digest, as seems to be the interpretation of education in the ordinary school. They search out special aptitudes and develop them; they deliberately take advantage of the strongly imitative and suggestible qualities, and exercise these qualities for good; in the absence of any ability on their own part to build up a true morality, the children are given a superficial morality by punishment or deprivation when they do wrong, and reward or praise when they do right.

If the child is in the regular graded school room, it is very necessary to watch lest he be given tasks that are quite beyond him and pushed to the point of mental irritability. The knowledge acquired in school is much less important than the habits formed and the attitude toward life and work. A habit of failure acquired in school is as bad for the feeble-minded child as for the dull normal, and quite as often follows the child into his working life. If he is the type of defective who has insight into his own dulness, the habit of failure may be accompanied by a discouragement which is very difficult to overcome.

Two excellent examples of individual work with feeble-minded children in the community were observed by the writer in connection with work in an open air school, having two teachers for fifty pupils, and a resident nurse. One of these was a girl of thirteen and a half years who had been in the school for three years and in that time had completed only one grade. Physical examination on entrance and at the time observed showed nothing more than poor general condition. At the time of observation she had been promoted to the fifth grade, but was not by any means doing the work of that grade. By all forms of psychological tests she graded as feeble-minded, passing just over nine years by the Binet (1911) scale. The teacher's report was that she was abnormally quiet and reticent when she entered the school, but a likeable girl on the whole. Her dulness had been recognized, and she herself seemed quite as conscious of it as the teachers. The school's efforts to overcome her reticence showed excellent results in the girl's general attitude, though she was still very sensitive to her dulness. Some fear was felt when she left school at fourteen that her old reticence might make it difficult or impossible for her to fit into industrial life, but she found factory work at seven dollars a week and still kept the work when last heard from eight months later. 
The other pupil was a girl about whose age there was some doubt,- - the school giving her age as thirteen and a half and her mother as fourteen and a half. This girl was recommended to the open air school primarily as a conduct problem, although the grounds for admission were present in the very poor general physical condition. The history as given was that she had been growing more and more troublesome for a year past, and recently had become quite incorrigible in the class room. She would thrust her tongue out at the teacher, make faces at the other pupils, etc. The principal referring the girl thought it a case of beginning psychosis. She was in the fifth grade. An older brother had also been very troublesome during his last year at school, in the fifth grade, and had been transferred to the industrial room.

Psychological examination showed an unmistakably feebleminded girl, mental age by the Binet scale being less than nine years. When first admitted to the open air school she reacted in the class room as in the previous school, and gave considerable trouble even in the recess and rest periods. After two weeks trial, it was decided to take her out of the class room, but to let her remain in the school, taking her rest periods with the other pupils and helping the school matron during her class periods. Her improvement was so marked that the consent of the principal was asked for the continuance of the plan. There was no further conduct disturbance though she continued to be noisy and boisterous in play for the first few months. She remained for that school year, her only school work in that time being selected reading. On leaving school she found work in a factory at $\$ 7.50$ a week and was at the same work when last heard from eight months later.

The home as a factor in the training of a feeble-minded child is of course even more important than the school. Where the home is not in itself capable of giving adequate oversight, the assent and coöperation of the parents are manifestly necessary for supervision from the outside. Under authorized supervision from a central state agency, this question of coöperation would probably never arise, even though the actual visiting were delegated to local private agencies. It is unlikely, however, to arise in the case of any home that is capable of properly training and protecting a feeble-minded child. With the children themselves there is rarely any difficulty in approach,- they do not question motives as the normal child. 
The parents should be told very frankly any special points in the diagnosis and recommendation and be given specific instructions from time to time as to methods of handling the child. Especially should they be warned of the necessity for the formation of regular habits and the dangers of overstimulation. Ways of fostering the socially positive qualities of the child and combating the negative qualities should be gone over in "words of one syllable," if need be. All work should be directed to the formation of good habits and the avoidance of bad.

Ways of keeping the child's interest in the home should be devised; a habit of reading should be encouraged and books selected for their possibilities of pointing a simple moral without any special stimulation; simple games that give the child a fair chance to win should be provided from outside if the family cannot provide them. Any musical ability or interest of the child should be fostered.

While the child is still in school the question of the kind of work he is likely to do later should be considered. It is well to plan for this as near the home as possible to avoid the expense of carfares and the many undesirable distractions that car-riding involves. Lack of ability to do certain forms of work does not handicap the feeble-minded so much as lack of ability to attend to the job. For the child who has been deliberately trained to a fair degree of stickto-itiveness, this will be much less of a handicap and he should fit very fairly into many forms of unskilled factory work.

Possible employers should be interviewed and interested in the practicability of employing such children. Their response is often surprising. They take the rather sensible stand that it is as well to employ people about whom the worst is known as to run the chance of getting the same people through the regular employing channels and know nothing of them. One of the most encouraging and heartening experiences that come to the tired social worker is the encounter with the kindly employer or foreman who says he is willing to give the defective child a chance and who gives much more than a chance; the effect of his friendly supervision is shown later in his confidential opinion that the doctor who said that particular child was feeble-minded doesn't know his business. This kind of an employer and especially this kind of a foreman is really not an isolated instance.

A point to be especially emphasized in work suitable for the 
feeble-minded is the possibility for supervision. The best and most complete special training can never make of the defective anything but a helper. There is no exception here even in the case of those defectives who have special abilities along certain lines, for although they may be able to do the actual work done by a carpenter or a plumber, they cannot plan as a carpenter or a plumber, or work independently.

Both social workers who give supervision and even more the families of the feeble-minded persons are apt to forget that a fair amount of recreation is as necessary for the defective as for the normal, and that it is quite natural that he should desire the particular forms of recreation the rest of the community enjoy. Games in the home, music, reading, fancy work, are not sufficient when all the rest of the world, including other members of his own family, are attending moving pictures or a band concert. Outside recreation should be planned for in a degree which does not cause overstimulation, and under supervision which is not so obvious as to arouse antagonism.

In dealing with the adult feeble-minded individual who has been recognized as such for the first time as an adult, one realizes that the most important part of the program of work for the feeble-minded is the provision for methods of early diagnosis. As found, he presents a problem of mental defect with all that it implies of lack of judgment and control plus well established habits that are difficult or impossible to break. If these habits happen to be actively antisocial we have what is so popularly known as the defective delinquent. Treatment of this type outside an institution is practically never successful and institution directors who have dealt with them will say that treatment within any ordinary institutions is quite as unsuccessful. Mental instability is more prominent than mental defect in practically all of these cases,-they are not merely untrained feeble-minded. The mental defect, however, is there, and the community should treat them not as delinquents but as the doubly defective individuals that they are.

Work to make the defective safe for the community should go side by side with effort to make the community safe for the defective. This to be effectual must cover a wide range, from education of the community on the significance of feeble-mindedness and the necessity of special provision, to the enforcement of all laws for the protection of children and the security of public morals. 
Just as the methods found specially adapted to the teaching of the feeble-minded have contributed much to the educational methods applied to the normal child, so the social treatment of the defective on the individualistic basis is bound to point the way for better methods of dealing with social problems among the normal. So-called individual work with the normal group is much more frequently personal than individual, and failure in the social handling of the normal individual is undoubtedly often due to this fact. The obvious defects in the feeble-minded make it necessary to search out and determine the value of any positive qualities that he may possess and weigh them against the defects. The psychologist or psychiatrist in interpreting the individual furnishes a basis upon which truly constructive work may be done, when the social worker knows the best and can foster it and knows the worst and can fight it. 